\title{
Take five
}

We celebrate our fifth birthday this issue, with some reflections on the journey from 2016 to today.

N ature Energy launched five years ago this month. It came immediately in the wake of the Paris Agreement and the beginning of the UN Sustainable Development Goals. Both frameworks recognised the importance of energy system decarbonization and, despite their weaknesses, made it clear that the energy transition was essential. The scale of the challenge was obviously enormous and had long been recognised as such. It remains so today, although there continue to be reasons to be optimistic.

The past five years have certainly been turbulent. It's hard to imagine that many scenario exercises or forecasts could have predicted some of what we've experienced, particularly in recent months.

But it's our birthday and it's the start of a new year - now is a time for celebration. Rather than dwell on gloominess, let's reflect on the recent positives. Many countries (including China), cities and other regions have committed to net-zero emissions targets by 2050 or 2060 . Electric vehicle sales have grown worldwide and their charging infrastructure has become increasingly commonplace on streets and roads. Solar and wind power prices have dropped faster than many expected; these sources have become the cheapest forms of electricity in many locations around the world. Children made caring about energy cool.

This progress has taken time and it has been gradual. The journey is far from over and there is more needed, both to develop and implement the solutions required, to speed the transition and to make it a just and equitable one. Our work is far from over. Yet it seems fair to say that the direction of travel is increasingly clear now, making the work that much easier - and, dare we say it, maybe that much more exciting.

When Nature Energy launched in 2016, it was as what we call a thematic journal. That is, we orient ourselves around the topic of energy rather than specific disciplines (such as materials science or economics) that might encompass it. In this way, in our first editorial we highlighted the need for a multiplicity of voices to come together for the benefit of one another in addressing the critical challenges for the energy transition. We set ourselves the aim to "be a home for the many different voices needed, publishing the best research and opinion on energy issues across the natural and social sciences."

In this celebratory issue, we return to this idea of different voices in two new ways for us.

First, we wanted to hear from researchers who have also been starting out on their own journeys during these past five years. This issue thus includes five Viewpoints from early career researchers (Michael Saliba, Behnam Ghalei, Huilin Pan, Leah Stokes and Evangelia Spyrou) who have all authored papers with us since we launched. These researchers each reflect on aspects of their career so far that were important to them. Together they reveal a diverse set of experiences, underscoring the challenges but also some of the pleasures faced in early academic life today.

Our second approach is our Feature, in which both current and former editors of Nature Energy look back at some of our favourite papers from the past five years. Our aim with this piece is to showcase the variety of exciting research studies it has been our privilege to read and publish. We've also tried to explain some of the reasons why the papers stood out to us and what we thought was particularly exciting about them.

It's rare that we editors publicly voice opinions on past publications but we hope you'll indulge us given the occasion. It's our hope that the Feature provides some insights into how we approach the task of selecting manuscripts for peer review and some of the things that motivate our thinking. Ultimately, we hope it goes some way to illustrate our passion for the communities we try to serve.

And we couldn't do any of this without the communities you - our readers, authors and reviewers - represent. So we would like to take this opportunity to thank the over 3,100 authors who've published with us so far and the more than 2,700 reviewers who've helped us in evaluating submissions. We are eternally grateful to you all for your advice, your support and your time.

Whether or not we're achieving the aims we set ourselves five years ago is too early to say but also perhaps not for us to judge. Nonetheless, we like to think we've been doing - and will continue to do - our best to make space for different disciplines and different issues to be discussed in our pages. There is still a lot we can do to meet this aim and we will continue to strive towards it, to help support academia, industry and policy to build the energy systems of the future. We look forward to working with you all over the next five years.

Published online: 21 January 2021 https://doi.org/10.1038/s41560-021-00774-0 